\title{
Docosahexaenoic Acid Deficit Is Not a Major Pathogenic Factor in Peroxisome-Deficient Mice
}

\author{
A. Janssen, M. Baes, P. Gressens, G.P. Mannaerts, P. Declercq, and \\ P.P. Van Veldhoven
}

Laboratory of Clinical Chemistry (AJ, MB, PD), Faculty of Pharmaceutical Sciences, and Department of Pharmacology (GPM, PPVV), Faculty of Medicine, K.U. Leuven, B-3000 Leuven, Belgium; and Laboratoire de Neurologie du Développement (PG), Hôpital Robert-Debré, Paris, France

\begin{abstract}
SUMMARY: Docosahexaenoic acid (DHA), a major component of membrane phospholipids in brain and retina, is profoundly reduced in patients with peroxisome biogenesis disorders (Zellweger syndrome). Supplementing newborn patients with DHA resulted in improved muscular tone and visual functions. The purpose of this study was to investigate (a) whether DHA levels were also reduced in newborn PEX5 knockout mice, the mouse model of Zellweger syndrome that we recently generated; (b) whether these levels could be normalized by supplying DHA; and (c) whether this results in longer survival. The DHA concentration in brain of newborn PEX5 $5^{-1-}$ mice was reduced by $40 \%$ as compared with levels in normal littermates; in liver, no differences were noticed. The daily administration of $10 \mathrm{mg}$ of DHA-ethyl ester (EE) to pregnant heterozygous mothers during the last 8 days of gestation resulted in a normalization of brain DHA levels in Zellweger pups. However, no clinical improvement was observed in these pups, and the neuronal migration defect was unaltered. These data suggest that the accretion of DHA in the brain at the end of embryonic development is not only supported by the maternal supply but also depends on synthesis in the fetal brain. Furthermore, the DHA deficit does not seem to be a major pathogenic factor in the newborn Zellweger mice. (Lab Invest 2000,
\end{abstract} 80:31-35).

$T$ he cerebro-hepato-renal syndrome of Zellweger is a fatal inherited disease caused by a deficient import of peroxisomal matrix proteins. Zellweger patients suffer from extreme hypotonia and psychomotor retardation and usually die within their first year of life (Lazarow and Moser, 1989). The most prominent metabolic changes due to peroxisome dysfunction are a depletion of ether phospholipids and an accumulation of substrates of the peroxisomal $\beta$ - and $\alpha$-oxidation pathways including very long chain fatty acids, pristanic acid and bile acid intermediates, and phytanic acid, respectively.

A profound deficiency of docosahexaenoic acid (DHA) ( $<30 \%$ of normal levels), a $n-3$ polyunsaturated fatty acid (PUFA), has been documented in Zellweger patients (Martinez, 1992a). This reduction is specific for DHA because the levels of other PUFA, including arachidonic acid, are not significantly altered. DHA $(\mathrm{C} 22: 6 n-3)$ is synthesized from the essential fatty acid $\alpha$-linolenic acid (C18:3n-3) by successive elongation

Received August 30, 1999.

This work was supported by grants from the FWO Vlaanderen (G0.0280.97 and G0.0204.99), Geconcerteerde Onderzoeksacties K.U. Leuven (GOA/99/09), and by Biomed BMH4-CT98-3569. A.J. is a fellow of the IWT and M.B. is a research associate of the FWO Vlaanderen. Address reprint requests to: Dr. P. Van Veldhoven, Department of Pharmacology, Faculty of Medicine, K.U. Leuven, Herestraat 49, B-3000 Leuven, Belgium. Fax:016 345699; E-mail:Paul.VanVeldhoven@med.kuleuven.ac.be; Dr. M. Baes, Laboratory of Clinical Chemistry, Faculty of Pharmaceutical Sciences, K.U. Leuven, Herestraat 49, B-3000 Leuven, Belgium. Fax: 016 347281; E-mail: Myriam.Baes@uz.kuleuven.ac.be and desaturation reactions similar to the synthesis of arachidonic acid (C20:4n-6) from linoleic acid (C18:2n6). However, an alternative pathway for DHA synthesis has been described (Voss et al, 1991), whereby $\mathrm{C} 22: 5 \mathrm{n}-3$ is not directly converted to C22:6n-3 by a $\Delta 4$-desaturase but is first elongated to C24:5n-3 and desaturated to $\mathrm{C} 24: 6 n-3$. In a final step the latter is thought to be $\beta$-oxidized in peroxisomes to $\mathrm{C} 22: 6 \mathrm{n}-3$, explaining the selective DHA deficit in Zellweger patients (Reddy and Mannaerts, 1994; Voss et al, 1991).

DHA is the major PUFA in the adult mammalian brain and retina where it occurs esterified in membrane phospholipids (Sastry, 1985) and seems to play an essential role in the membrane biophysical properties (Scott and Bazan, 1989). Dietary deficiency of $n-3$ fatty acids is associated with disturbances in vision and other neurological abnormalities (Green and Yavin, 1998). A rapid accretion of DHA that starts during the last period of gestation and continues for a short time after birth has been documented in man and in rat (Martinez, 1992b; Green and Yavin, 1996).

Because Zellweger patients have a manifest deficit of DHA, Martinez supplemented several patients (3-7 months old) with DHA-EE (Martinez, 1996; Martinez and Vazquez, 1998). Beneficial effects were noticed including increased muscular tone, better visual function, and improvement of myelination. However, for ethical reasons, no non-treated control group was taken. Similar DHA-EE therapy of a severely affected Zellweger patient by Suzuki et al (1996) could not prevent neurological deterioration, suggesting that pa- 
tients with a milder phenotype would be better candidates for DHA supplementation. It should be noted that Zellweger syndrome is a descriptive term and that recent molecular tools have shown that these patients belong to 10 different complementation groups (Moser et al, 1995).

We recently generated an animal model for Zellweger syndrome through inactivation of the murine PEX5 gene that encodes the import receptor of most peroxisomal matrix proteins (Baes et al, 1997). Neurodevelopmental and biochemical analyses confirmed that the PEX5 knockout mice are a good representation of Zellweger syndrome. The mice are hypotonic at birth, are growth retarded, have a neuronal migration defect, and die within 72 hours after birth. In this report we examined whether the Zellweger mice already have a DHA deficit at birth and whether this could account for some of the observed pathology.

\section{Results}

\section{DHA Deficit in Tissues of PEX5 ${ }^{-/-}$Mice}

To evaluate whether PEX5 knockout mice (Zellweger mice) have a DHA deficit at the time of birth, tissues of newborn $\mathrm{PEX} 5^{-1-}$ mice and of control littermates were analyzed. Phospholipids were extracted from liver and brain, and their fatty acids were transmethylated for GC analysis. Column conditions were optimized to quantify C22:6n-3, C20:4n-6, and hexacosanoic acid (C26:0). Typical fatty acid methyl ester (FAME) GC profiles of brain extracts of a PEX5 ${ }^{-1-}$ and a PEX $5^{+/+}$mouse are shown in Figure 1.

The DHA content in brain phospholipids of PEX5 ${ }^{-/-}$ mice was $40 \%$ lower than in control littermates, $\mathrm{PEX}^{+/-}$mice, and PEX5 ${ }^{+/+}$mice as shown in Figure 2. The heterozygous mice did not differ from wild-type mice. On the contrary, in liver, there was no difference in DHA content between PEX5 $5^{-/-}$and control animals (Fig. 2).

If DHA is indeed synthesized according to the scheme proposed by Voss et al (1991), a decrease in DHA should be accompanied by an accumulation of C24:6n-3. A FAME, eluting ahead of the internal standard, was consistently present in $\mathrm{PEX} 5^{-1-}$ brain extracts, whereas it was hardly detectable in controls. By spiking the extracts with synthetic C24:6n-3, the peak was tentatively identified as C24:6n-3.

\section{Supplementation of DHA to PEX5 ${ }^{-/}$Fetuses}

Pregnant heterozygous mothers $\left(\mathrm{PEX} 5^{+/-}\right)$were treated with $10 \mathrm{mg}$ of DHA-EE daily, starting at embryonic day 10.5 (E10.5) until E18.5 or birth (P0.5). As a result, the DHA content in brain phospholipids of PEX5 ${ }^{-1-}$ pups normalized to the level of untreated control mice (Fig. 2). The DHA content in the brain of $\mathrm{PEX} 5^{+/-}$and PEX5 ${ }^{+/+}$pups was also slightly elevated after treatment.

The normalization of DHA levels in newborn $\mathrm{PEX}^{-\prime-}$ mice, however, did not result in clinical improvement. The mice were growth retarded at birth to the same extent as PEX5 ${ }^{-1-}$ mice from non-treated

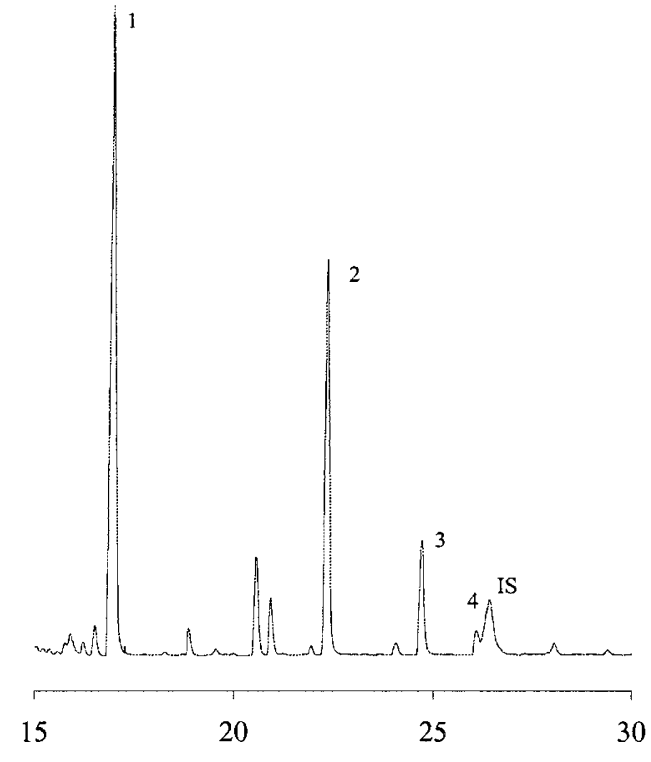

b

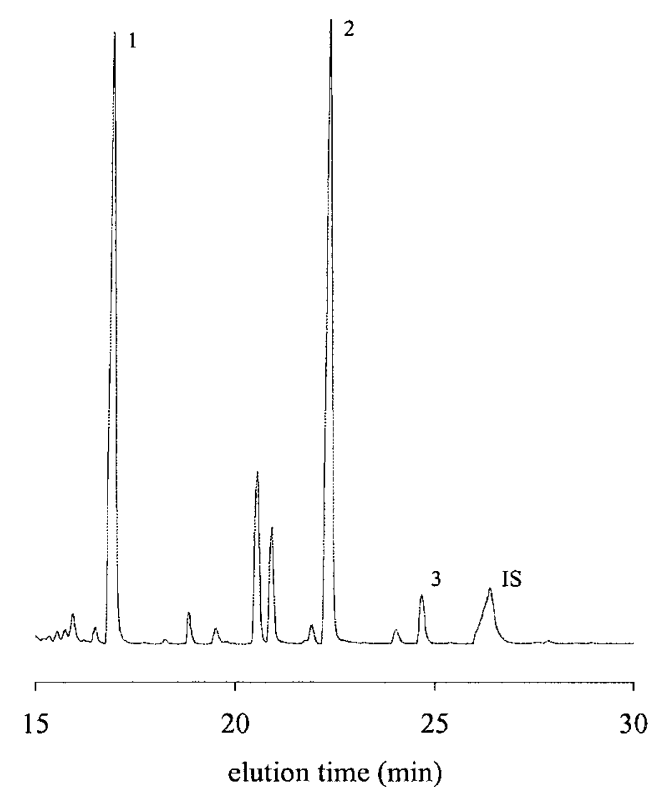

Figure 1.

GC analysis of long chain fatty acids in brain. Transmethylated fatty acids from the brain phospholipids of a PEX5 $5^{-1-}$ mouse (a) and of a PEX $5^{+/+}$mouse (b) were separated on a BPX70 column. The FID response during 15 and 30 minutes is shown. As described in "Materials and Methods," the temperature at 15 minutes was $181^{\circ} \mathrm{C}$ and the temperature gradient was $3^{\circ} \mathrm{C} /$ minute. The numbered peaks correspond to the following compounds: $1, \mathrm{C} 20: 4 n-6 ; 2$, C22:6n-3; 3, C26:0; and 4, C24:6n-3. IS represents the internal standard C27:0.

mothers (30\% reduction in body weight as compared with control littermates) (Baes et al, 1997). They displayed a deep hypotonia preventing them from supporting themselves and sucking. Similar to non- 


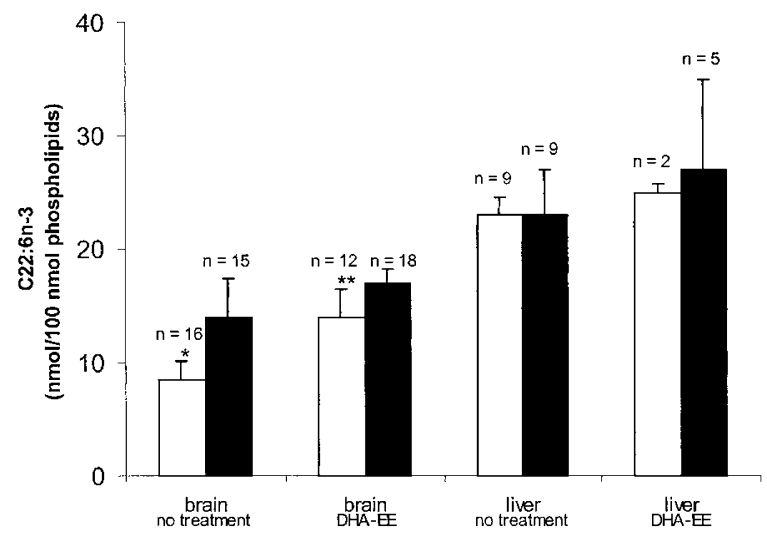

Figure 2.

DHA content of the brain and liver phospholipids. Brain and liver of PEX5 ${ }^{-1-}$ pups (open bars) and control pups (PEX5 $5^{+/-}$and PEX5 $5^{+/+}$) (closed bars) from untreated and DHA-EE-treated mothers were extracted, and DHA was quantified in the phospholipid fraction. The data are presented as mean \pm SD. Statistical analysis was done by one-way ANOVA. * Significantly different from control; ** significantly different from untreated PEX5 ${ }^{-1-}$ brain.

treated PEX5 ${ }^{-/-}$mice, they usually died within a day after birth. Brains of DHA-treated Zellweger pups fixed with $4 \%$ formaldehyde were examined by cresylviolet staining to evaluate whether the DHA supplementation could have reversed the neuronal migration defect. However, no difference in cell densities in the cortical plate and in the intermediate zone was observed between DHA-treated and untreated newborn PEX5 $^{-1-}$ mice (Fig. 3).

In several of the Zellweger patients treated with DHA by Martinez (Martinez, 1996; Martinez et al, 1993), the increase of DHA levels was accompanied by an increase of the vinyletherphospholipids (plasmalogens) in erythrocytes and a decrease of C26:0 levels in plasma. Analysis of the brain phospholipid fraction of DHA-treated PEX5 ${ }^{-1-}$ mice revealed that the plasmalogen levels were somewhat increased but remained extremely low (Table 1) and that C26:0 accumulated to the same extent as in non-treated PEX5 ${ }^{-/-}$mice (Table 1).

\section{Discussion}

Although the lack of DHA in Zellweger patients is well established during the first months of life (Martinez, 1992a), it is not known whether this already occurs during fetal development. In other words, it is unsure whether the fetus is responsible for its own production of DHA or whether the mother can supplement sufficient DHA by placental transfer to the developing embryo. It has been documented that the fetal rat brain is capable of synthesizing DHA from its linolenic acid precursor through elongation/desaturation, but the quantitative contribution to the critical DHA accretion in the brain is not known (Green and Yavin, 1993, 1998). Our findings that functional peroxisome deficiency in the developing mouse fetus results in a $40 \%$ reduction of DHA content in the brain at birth as compared with wild-type littermates, indicate that the fetal brain is in part responsible for its own DHA a

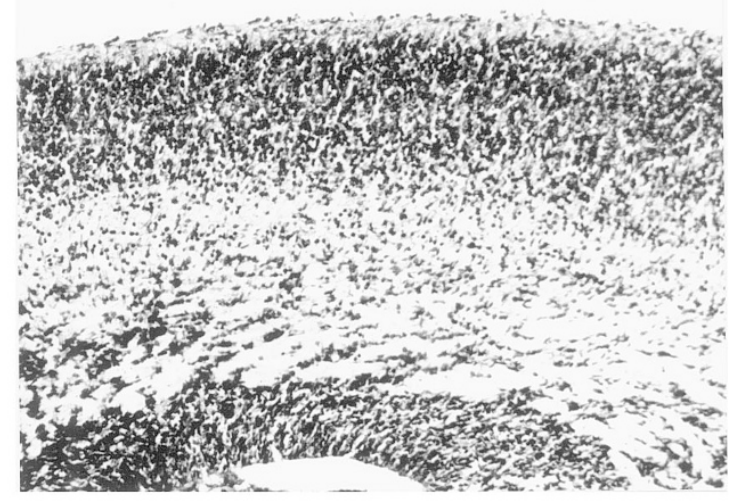

b

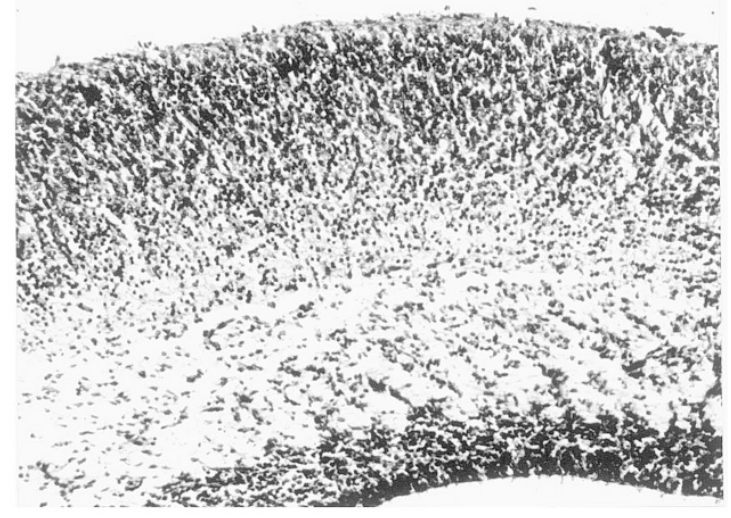

C

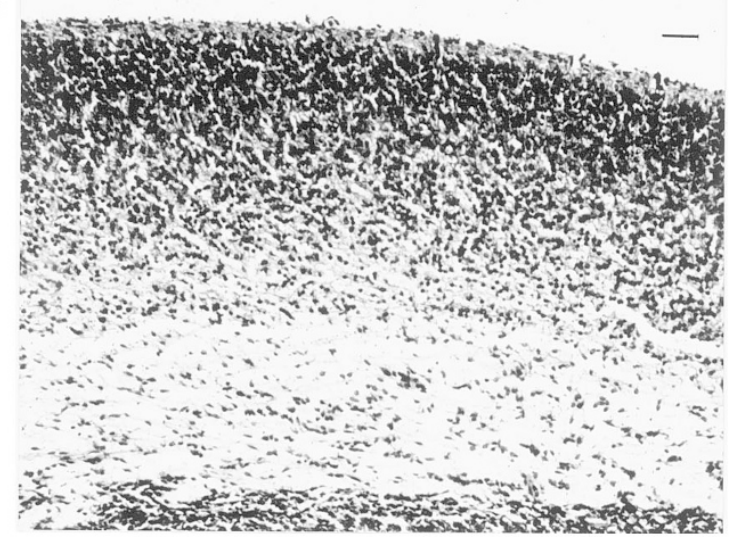

Figure 3.

Neuronal migration defect in PEX5 ${ }^{-1-}$ mice. Sections of the cortex of newborn mice were stained with cresylviolet. (a) PEX5 $5^{-1-}$, untreated; (b) PEX5 ${ }^{-1-}$ DHA-EE treated; (c) PEX $5^{+/+}$, untreated. Magnification bar is $40 \mu \mathrm{m}$.

synthesis from the precursors provided by the mother. In the cerebrum of Zellweger patients between the ages of 1 and 8 months, a much more severe $70 \%$ reduction of DHA content has been reported (Martinez, 1992a). Unless this discrepancy is related to species differences, this seems to suggest that the peroxisome-deficient brain acquires significant amounts of DHA from the mother during fetal development but becomes severely depleted after birth. The observation that in liver of newborn PEX $5^{-/-}$mice no DHA deficit occurs indicates that the maternal 
Table 1. VLCFA and Plasmalogens in the Brain of Newborn Zellweger and Control Mice

\begin{tabular}{cccccc}
\hline & \multicolumn{2}{c}{ PEX5 $^{-/-}$} & & \multicolumn{2}{c}{ PEX5 $^{+/-}$and PEX5 ${ }^{+/+}$} \\
\cline { 2 - 3 } \cline { 5 - 6 } Treatment & No & DHA-EE & & No & DHA-EE \\
\hline C26:0 & $3.3 \pm 0.18$ & $3.6 \pm 0.18$ & & $1.2 \pm 0.06$ & $1.3 \pm 0.1$ \\
& $(n=16)$ & $(n=8)$ & & $(n=14)$ & $(n=12)$ \\
Plasmalogens & $0.24 \pm 0.03$ & $0.58 \pm 0.07$ & & $15.0 \pm 0.77$ & $15.7 \pm 0.19$ \\
& $(n=4)$ & $(n=11)$ & & $(n=12)$ & $(n=20)$ \\
\hline
\end{tabular}

C26:0 and plasmalogen (nmol/100 nmol phospholipids) content in the brain in PEX5 ${ }^{-1-}$ pups obtained from untreated or DHA-EE-treated mothers compared with the values of an untreated and a treated control group. The data are represented as means \pm SEM.

supply of DHA is sufficient to saturate the need for DHA in this organ. This is in contradiction with earlier findings that circulating DHA is preferentially taken up by the brain (Scott and Bazan, 1989). However, it is in line with the observation that after a single intraamniotic DHA-EE injection in fetal rats, a steeper increase of DHA was found in the fetal liver than in the brain (Green and Yavin, 1998).

Supplementing pregnant $\mathrm{PEX} 5^{+/-}$mothers with DHA gave rise to a normalization of the brain DHA content in the PEX5 ${ }^{-1-}$ pups. This means that the defect in fetal DHA synthesis can be adjusted by increasing the maternal supply of DHA.

In peroxisome-deficient patients as well as in peroxisome-deficient mice several abnormalities are already prominent at birth, including hypotonia and neuronal migration defects. In addition, in mice, an intrauterine growth retardation was observed (Baes et al, 1997; Faust and Hatten, 1997). Normalization of DHA levels in fetal Zellweger mice did not improve these symptoms, suggesting that the DHA deficit is not causally involved in these abnormalities. This is in contrast to the beneficial effect of DHA on muscular tone in Zellweger patients treated with DHA-EE (Martinez, 1996; Martinez and Vazquez, 1998). A possible explanation for this discrepancy might be that the mice were treated for a much shorter time period (10 days), not allowing visible clinical improvements. Unfortunately, because of the early postnatal death of Zellweger mice, prolonged administration of DHA was not possible. In addition, a potential beneficial effect on visual functions and myelination could not be evaluated in the newborn mouse. We did not observe changes either in plasmalogen levels or in C26:0 levels in brain of DHA-treated Zellweger mice, which is in contrast to the findings in DHA-treated Zellweger patients (Martinez et al, 1993). It should be noted that in the patients, plasmalogens and C26:0 were analyzed in erythrocytes and in plasma, respectively, whereas in DHA-treated mice, the phospholipid fraction of the brain was used. The shorter DHA treatment period in PEX5 $5^{-1-}$ mice could also account for this apparent disagreement.

In conclusion, the DHA deficiency in brain during embryonic development of peroxisome-deficient mice does not seem to cause the observed neurodevelopmental abnormalities.

\section{Materials and Methods}

\section{Administration of DHA-EE}

Ten milligrams of DHA-EE (Sigma, Bornem, Belgium) were administered daily by tube feeding as an emulsion of $10 \%$ DHA-EE in $1 \%$ methylcellulose to pregnant heterozygous mothers $\left(\mathrm{PEX} 5^{+/-}\right)$, starting at E10.5 until E18.5 or P0.5.

\section{Lipid Extraction and Separation of Lipid Fractions}

All solvents were of the highest quality commercially available (Acros, Geel, Belgium) and were supplemented with $0.05 \%$ butylhydroxytoluene (Acros) to prevent lipid peroxidation.

Whole tissues (brain, approximately $80 \mathrm{mg}$, and liver, approximately $45 \mathrm{mg}$ ) of PEX5 ${ }^{+/-}$and PEX5 ${ }^{-/-}$ mice at E18.5 or P0.5 were homogenized in $3 \mathrm{ml}$ of $\mathrm{CH}_{3} \mathrm{OH} / \mathrm{CHCl}_{3}$ (2:1) using a Polytron homogenizer. The total lipid fraction was isolated as described (Van Veldhoven and Bell, 1988), dried, and dissolved in 0.5 $\mathrm{ml}$ of $\mathrm{CHCl}_{3}$.

Neutral lipids, fatty acids, and phospholipids were separated using an amino-column (Bond-Elut; Varian, Zaventem, Belgium). After equilibration with $3 \mathrm{ml}$ of heptane and $3 \mathrm{ml}$ of $\mathrm{CHCl}_{3}$, the lipid extract was applied and the neutral lipids, fatty acids, and phospholipids were eluted with, respectively, $4 \mathrm{ml}$ of $\mathrm{CHCl}_{3}$ :isopropanol $(2: 1), 4 \mathrm{ml}$ of $2 \%$ acetic acid in diethylether, and $4 \mathrm{ml}$ of methanol (Kaluzny et al, 1985). An aliquot of the methanol fraction was used for wet ashing, followed by determination of the phosphate content (Van Veldhoven and Bell, 1988).

\section{Determination of Fatty Acid Methyl Esters by Gas Chromatography}

As internal standards, $40 \mathrm{nmol}$ of $\mathrm{C} 17: 0$ (heptadecanoic acid) (Sigma) and $20 \mathrm{nmol}$ of C27:0 (heptacosanoic acid) (Sigma) were added to a 1-ml phospholipid fraction. The FAME obtained by transesterification were dissolved in $20 \mu$ l of heptane, and $0.5 \mu$ l was on column injected on a BPX70 column [70\% cyanopropyl (equiv.) polysilphenylene-siloxane, $30 \mathrm{~m}, 0.32 \mathrm{~mm}$ id, $0.25 \mu \mathrm{m}$ coating (SGE, Austin, Texas)], and a flame ionization detector was used. Injector and detector temperatures were $80^{\circ} \mathrm{C}$ and $300^{\circ} \mathrm{C}$, respectively. Separation of compounds on this column is a function of the length of the 
fatty acid and the number of double bonds present. Helium was used as a carrier gas, at a column pressure of 12 psi. A three-step temperature program was applied: after an initial time of 2 minutes at $80^{\circ} \mathrm{C}$, the temperature was raised to $160^{\circ} \mathrm{C}$ at a rate of $20^{\circ} \mathrm{C} /$ minute and held at $160^{\circ} \mathrm{C}$ for 2 minutes; in a second step, the temperature was raised to $240^{\circ} \mathrm{C}$ at a rate of $3^{\circ} \mathrm{C} /$ minute and held at $240^{\circ} \mathrm{C}$ for 10 minutes; and in a third step, the temperature was raised to $260^{\circ} \mathrm{C}$ at a rate of $20^{\circ} \mathrm{C} /$ minute and held at $260^{\circ} \mathrm{C}$ for 5 minutes. To prove the identity of $\mathrm{C} 22: 6 n-3$, FAME were also injected on a Econo-Cap EC-WAX (Carbowax) column (Alltech Europe, Lokeren, Belgium) and a Econo-Cap 1 (EC1) column (Alltech Europe). To identify C24:6n-3, 30 nmol of this compound (Customer synthesis; Nu-Chek-Prep, Elysian, Minnesota) were added to the extracts.

Quantities of fatty acids were determined based on internal standard (C27) and correlated to the phospholipid content as described.

\section{Determination of Plasmalogens}

The phospholipid fraction was analyzed for plasmalogen content by measuring the amount of acidreleased fatty aldehyde (Blank et al, 1975). Plasmalogen levels are expressed relative to the total amount of phospholipids in the extracts.

\section{Histological Analysis of the Brain}

Newborn mice were killed by decapitation. Brains were removed and fixed for 5 days in $4 \%$ paraformaldehyde. After paraffin embedding, 7- $\mu \mathrm{m}$ sections were cut coronally and stained with cresylviolet.

\section{Acknowledgements}

We thank Dr. Kathleen Croes for excellent advice and Ms. Els Meyhi for technical assistance.

\section{References}

Baes M, Gressens P, Baumgart E, Carmeliet P, Casteels M, Fransen M, Evrard P, Fahimi D, Declercq PE, Collen D, Van Veldhoven PP, and Mannaerts GP (1997). A mouse model for Zellweger syndrome. Nat Genet 17:49-57.

Blank ML, Cress EA, Piantadosi C, and Snyder F (1975). A method for the quantitative determination of glycerolipids containing O-alkyl and O-alk-1-enyl moieties. Biochim Biophys Acta 380:208-218.

Faust PL and Hatten ME (1997). Targeted deletion of the PEX2 peroxisome assembly gene in mice provides a model for Zellweger syndrome, a human neuronal migration disorder. J Cell Biol 139:1293-1305.

Green P and Yavin E (1998). Mechanisms of docosahexaenoic acid accretion in the fetal brain. J Neurosci Res 52:129136.
Green P and Yavin E (1993). Elongation, desaturation, and esterification of essential fatty acids by fetal rat brain in vivo. J Lipid Res 34:2099-2107.

Green P and Yavin E (1996). Fatty acid composition of late embryonic and early postnatal rat brain. Lipids 31:859-865.

Kaluzny MA, Duncan LA, Merritt MV, and Epps DE (1985). Rapid separation of lipid classes in high yield and purity using bonded phase columns. J Lipid Res 26:135-140.

Lazarow PB and Moser HW (1989). Disorders of peroxisome biogenesis. In: Beaudet AL, Scriver CR, Sly WS, and Valle D, editors. The metabolic basis of inherited disease. New York: McGraw-Hill, 1479-1509.

Martinez M, Pineda M, Vidal R, Conill J, and Martin B (1993). Docosahexaenoic acid: a new therapeutic approach to peroxisomal-disorder patients. Neurology 43:1389-1397.

Martinez M (1992a). Abnormal profiles of polyunsaturated fatty acids in the brain, liver, kidney and retina of patients with peroxisomal disorders. Brain Res 583:171-182.

Martinez M (1992b). Tissue levels of polyunsaturated fatty acids during early human development. J Pediatr 120:S129$\mathrm{S} 138$.

Martinez M (1996). Docosahexaenoic acid therapy in docosahexaenoic acid-deficient patients with disorders of peroxisomal biogenesis. Lipids 31:S145-S152.

Martinez M and Vazquez E (1998). MRI evidence that docosahexaenoic acid ethyl ester improves myelination in generalized peroxisomal disorders. Neurology 51:26-32.

Moser AB, Rasmussen M, Naidu S, Watkins PA, McGuinness M, Hajra AK, Chen G, Raymond G, Liu A, Gordon D, Garnaas K, Walton DS, Skjeldal OH, Guggenheim MA, Jackson LG, Elias ER, and Moser HW (1995). Phenotype of patients with peroxisomal disorders subdivided into sixteen complementation groups. J Pediatr 127:13-22.

Reddy JK and Mannaerts GP (1994). Peroxisomal lipid metabolism. Annu Rev Nutr 14:343-370.

Sastry $P$ (1985). Lipids of nervous tissue: Composition and metabolism. Prog Lipid Res 24:67-176.

Scott BL and Bazan NG (1989). Membrane docosahexanoate is supplied to the developing brain and retina by the liver. Proc Natl Acad Sci USA 86:2903-2907.

Suzuki Y, Shimozawa N, Imamura A, Fukuda Y, Ichihashi H, Orii T, and Kondo N (1996). Trial of docosahexaenoic acid supplementation on a Japanese patient with a peroxisome biogenesis defect. Acta Paediatrica Japonica 38:520-523.

Van Veldhoven P and Bell RM (1988). Effect of harvesting methods, growth conditions and growth phase on diacylglycerol levels in cultured human adherent cells. Biochim Biophys Acta 959:185-196.

Voss A, Reinhart M, Sankarappa S, and Sprecher H (1991). The metabolism of 7,10,13,16,19-docosapentaenoic acid to $4,7,10,13,16,19$-docosahexaenoic acid in rat liver is independent of a 4-desaturase. J Biol Chem 266:19995-20000. 